\title{
GEOSUL
}

\section{BANCO INTERAMERICANO DE DESENVOLVIMENTO (BID) NO ESPAÇO-TEMPO: UMA ANÁLISE CRÍTICA SOBRE SEU PAPEL NO FINANCIAMENTO DA INTEGRAÇÃO REGIONAL \\ José Alex Rego Soares ${ }^{1}$ \\ Marcio Bobik Braga²}

Resumo: O objetivo do artigo consiste em analisar a desempenho do BID enquanto banco de integração regional e o tratamento dispensado ao círculo vicioso crédito-renda no período de sua criação até o começo do século XX. Dadas as circunstâncias comumente apresentadas em regiões com alta desigualdade de renda, a promoção do crédito fica presa nesse circuito vicioso, pois só há acesso ao crédito quem possui renda. Assim sendo, problematizamos como o Banco Interamericano não foi capaz de se consolidar como uma instituição financeira internacional de primeira linha no Sistema Financeiro Mundial (SFM). O BID tampouco ocupa o espaço de agente facilitador da integração regional na acepção da compactação entre espaço e tempo como dinamizador do crédito, uma vez que o desenho institucional do BID impossibilita o crédito no processo de integração regional.

Palavras chaves: Exclusão Financeira. BID. Integração Regional. Crédito. Renda.

\section{INTER-AMERICAN DEVELOPMENT BANK (IDB) IN SPACE: A CRITICAL ANALYSIS OF ITS ROLE IN FINANCING REGIONAL INTEGRATION}

\begin{abstract}
The purpose of this paper is to analyze the IDB's performance as a regional integration bank and the treatment of the vicious credit-income circle from its foundation to the early twentieth century. Given the circumstances commonly presented in regions with high income inequality, credit promotion is caught in this vicious circuit, as there is only access to credit for those with income. Therefore, we problematize how he InterAmerican Bank was not able to consolidate itself as a world-class international financial institution in the World Financial System (WFS). Nor does the IDB occupy the space of facilitating agent of regional integration in the sense of compressing space and time in order to dynamize the credit, because the IDB's institutional design makes credit impossible in the regional integration process.
\end{abstract}

Key words: Financial Exclusion. IDB. Regional Integration. Credit. Income.

1 Universidade Católica de Campinas, Campinas - SP, Brasil, jalex.economia43@gmail.com, https://orcid.org/0000-0001-9188-5040.

2 Universidade de São Paulo, Ribeirão Preto - SP, Brasil, marbobik@usp.br, https://orcid.org/0000-0002-2582-0000 


\section{BANCO INTERAMERICANO DE DESARROLLO (BID) EN EL TIEMPO ESPACIAL: UN ANÁLISIS CRÍTICO DE SU PAPEL EN EL FINANCIAMIENTO DE LA INTEGRACIÓN REGIONAL}

Resumen: El propósito de este documento es analizar el desempeño del BID como banco de integración regional y el tratamiento del círculo vicioso de los ingresos crediticios desde su inicio hasta principios del siglo XX. Dadas las circunstancias comúnmente presentadas en regiones con alta desigualdad de ingresos, la promoción del crédito se ve atrapada en este circuito vicioso, ya que solo hay acceso al crédito para aquellos con ingreso. Por lo tanto, problematizaremos como el Banco Interamericano no fue capaz de consolidarse como una institución financiera internacional de clase mundial en el Sistema Financiero Mundial (SFM). EI BID tampoco ocupa el espacio de agente facilitador de la integración regional en el sentido de la compresión entre el espacio y el tiempo como motor de crédito, pues el diseño institucional del BID hace imposible el crédito en el proceso de integración regional.

Palabras Clave: Exclusión Financiera. BID. Integración Regional. Crédito. Ingresos.

\section{Introdução}

Com o advento da criação do Banco Interamericano de Desenvolvimento (BID), criou-se uma grande expectativa sobre o papel que essa instituição poderia ter no futuro do desenvolvimento da América Latina. Imaginava-se que ela poderia responder aos problemas do desenvolvimento da região, formando um conjunto harmônico e complementar às outras instituições que surgiram após Bretton Woods ${ }^{3}$. Nesse artigo faremos uma análise crítica sobre o papel do BID em relação a sua atuação na compactação do território (integração) e sua autonomia financeira.

Um dos desafios lidados por um modelo de desenvolvimento soberano na região é a constituição de sistema de financiamento que possa responder de forma autônoma ao desenvolvimento regional e criar mecanismos de integração regional. Desta forma, proporcionamos uma interpretação a respeito do papel das instituições de fomento na América Latina a partir de uma interpretação crítica do BID.

\footnotetext{
${ }^{3}$ Bretton Woods é a denominação dada ao novo arranjo internacional pós-segunda guerra mundial. A nova Governança global que surge tem seus pilares baseado no dólar com moeda internacional, o dólar lastreado pelo ouro e criação de um conjunto de instituições internacionais para dar suporte à nova ordem econômica mundial- Fundo Monetário Internacional (FMI, Banco Mundial (BM) e Banco Internacional para Reconstrução e Desenvolvimento (BIRD).
} 
Entendemos que o papel do crédito precisa ser reinterpretado para além da lógica financeira crédito renda, como nos propomos a discutir. Nesse sentido, o objetivo do artigo consiste em analisar o desempenho do BID enquanto banco de integração regional e o tratamento dado ao círculo vicioso crédito-renda. Em outros termos, só há acesso ao crédito quem possui renda. Buscaremos responder a seguinte questão: $O$ Banco se constituiu ou não numa instituição financeira internacional de primeira linha no Sistema Financeiro Mundial (SFM)? Teve ele um papel de agente facilitador da integração regional na acepção da compactação entre espaço e tempo?

Assim podemos descrever se o BID surge como um banco da integração, uma instituição de fomento capaz de gerar sinergias, aglutinar e desencadear projetos de desenvolvimento regional, e, no limite, como um estabilizador macroeconômico da região.

Frente às condições concretas que se apresentaram na conjuntura política, histórica e econômica, analisaremos os desdobramentos das ações do BID neste cenário que se estabelece nos seus primeiros anos de funcionamento. Dado aos parcos recursos dos quais dispunha inicialmente e á falta de uma linha de ação, não havia uma concepção de força que o capacitasse para atuar com projetos de integração.

Não se pretende aqui ser exaustivo na análise histórica. Entretanto, é necessário traçar uma linha de análise sobre as condições do financiamento da integração regional e a compressão do espaço tempo a partir da atuação dessa instituição como um banco de desenvolvimento.

Desta forma, o artigo estará dividido em quatro tópicos, além desta introdução e das conclusões. No primeiro, iniciamos uma abordagem teórica à luz do tratamento das finanças no espaço, que são "relaciones sociales que ocurren a lo largo del espacio y el tiempo" (JESSOP, 2007, p.33).

A partir do espaço socialmente delimitado que se expõe a condição de exceção aos serviços financeiros pelos quais "classes sociais ou regiões menos favorecidas minorias sociais têm o acesso aos serviços financeiros tradicionais negados" (CROCCO; JAYME JR, 2006, p. 14). Em termos gerais, vamos discutir o conceito de exclusão financeira, com o conceito de espaço econômico e as ações do BID. 
No segundo tópico, analisaremos o papel do BID na integração regional como uma instituição de fomento no processo de integração e os limites que se depositam. No terceiro, analisaremos o BID no sistema financeiro mundial e sua autonomia financeira e política considerando as condições geopolíticas e históricas. Enfim, no quarto tópico, buscaremos entrar na análise contemporânea sobre o papel do BID e as instituições de fomento, no que diz respeito ao desenvolvimento e à integração regional, bem como sua relação com o Sistema Financeiro Mundial e capacidade de romper o ciclo crédito-renda.

\section{Da Exclusão Financeira}

O financiamento do desenvolvimento regional é uma condição do desenvolvimento econômico. Para tanto, ao jogarmos luz sobre essa temática em específico, precisaremos nos pautar em parâmetros teóricos para constituir nossa abordagem. Destarte, lançaremos mão da análise conceitual da exclusão financeira - 0 suporte teórico do conceito de exclusão financeira nos pautará para a análise das operações de crédito praticadas pelo BID e seu lugar no tempo espaço. As explorações em termos de pesquisa teórica e empírica desenvolvidas por autores como Leyshon (1995), Leyshon; Thrift (1997) e Dymsky (2005, 2007), nos pautarão a respeito do espaço e a exclusão financeira 4 .

Ao cabo, procuramos construir uma análise vinculada à apreciação do espaço econômico e ao papel das finanças na inclusão entre os espaços, ou mesmo da exclusão financeira nos reflexos para o processo de integração regional da América Latina a partir das políticas de crédito do BID.

Observamos que o debate que sucedeu a criação do BID não esteve diretamente articulado com uma percepção do espaço, apesar de estar fortemente

\footnotetext{
${ }^{4}$ Aqui estamos concentrando nossa abordagem da exclusão financeira com uma escassez de créditos a fim de comprimir tempo e espaço, Dymski (2005) nos traz uma justa definição: "So the idea of 'financial exclusion' has provided a unified way of viewing financial processes and comparative institutional arrangements in lower-income and upper-income societies. Its articulation has involved a generalization of the idea of race-based discrimination in banking markets, to encompass customer-class distinctions other than race and ethnicity per se. This new terminology also opened the way to bolder and more extensive comparative analyses of national and regional credit and banking markets" (Dymski, 2005, p. 441).
} 
ancorada numa perspectiva regional (SOARES, 2016). No mais, não encontramos de forma articulada uma abordagem teórica do espaço econômica, possibilitando opções estratégicas selecionadas para o desenvolvimento social. $O$ nexo primordial entre espaço-tempo apresentado por Jessop, não se materializa5:

i) Desde la división espacial del trabajo entre campo y ciudad, entre norte y sur, entre diferentes economías a nivel regional, nacional e inclusive continental; ii) desde la territorialización del poder político, processo de formación estatal, a la dialética de las influencias internas y externas sobre la vida 'política; y por último, iii) desde diferentes imaginarios espaciales y de escala así como diferentes representaciones del espacio (JESSOP, 2007, p. 33-34).

Entendemos que, no ato da constituição de um Banco de Desenvolvimento para a América Latina, havia uma carência de elaboração teórica acerca do espaço econômico e consequentemente de sua compreensão. Em sua essência, o BID cumpriria como meta central alavancar o financiamento do desenvolvimento regional. Entretanto, ainda carecia de uma elaboração teórica mais consistente a partir da realidade histórica e política da América Latina no que diz respeito, aos espaços econômicos.

O financiamento de um conjunto de projetos específicos para a região esteve focado no primeiro momento como resposta ao subdesenvolvimento e à falta de poupança interna, enquanto resposta ao desincentivo dos países atuarem de forma mais altiva em estratégias de integração regional, contudo, essa abordagem passa ao largo a questão da exclusão financeira.

As propostas de financiamento (ofertas de crédito) seriam uma resposta antes à escassez de crédito e ao desenvolvimento desigual do que propriamente à exclusão financeira (LEYSHON; THRIFT, 1997). No decorrer do tempo, observamos a falta de maturação de um sistema de crédito (organizado pelo BID) capaz de organizar a

5 Uma releitura de Jessop da teoria do Espaço de Gramsci. Gramsci não vai conceder o espaço como algo que existe em si próprio, de forma independente das relações sociais particulares que constroem, reproduz e ocorre nele (Jessop, 2007). 
expansão geográfica do mercado por meio de uma seqüência de crédito, onde antes não existiria uma continuidade.

Logo, "A necessidade de anular o espaço pelo tempo pode, em parte, ser compensada pelo surgimento de sistema de crédito" (HARVEY, 2005, p.51), a fim de comprimir um "[...] horizonte de tempo e espaço" (HARVEY, 1989, p 89), num processo de concentração espacial, tarefa inicialmente que teria que ser cumprida pelo BID na prospecção desse espaço para integração.

A articulação entre essas duas esferas, tempo e espaço, via um sistema de crédito autônomo em relação aos centros financeiros internacionais, conduzido por uma instituição de fomento regional, torna-se condição primordial para propiciar um desenvolvimento na região que fosse adequado para dinamizar as economias da América Latina (AMIN; THRIFT, 1994). Desta forma, o BID teria que cumprir um papel de agente deflagrador de um sistema de crédito voltado para a região, como forma de superar condições históricas baseadas no sistema clássico de risco.

Essa condição era de suma importância para o rompimento do ciclo de renda e crédito. Em outras palavras, o mesmo estaria disponível em regiões com alta densidade de renda e, por sua vez, a renda gera mais crédito - uma típica condição de causação acumulativa, na esfera financeira ${ }^{6}$.

Esse sistema de risco acaba por aprofundar ainda mais as contradições entre centro e periferia, o local e o global, tempo e o espaço, empobrecendo as regiões internamente. Conforme destacou Leyshon e Thift (1997, p. 229-230). "[in] other words, rich areas to get poor areas poorer because of the way in which the financial system discriminates between people and communities on the basis of risk".

O BID teria como função suprir essa contradição espacial e conseqüentemente tornar-se uma resposta a essas contradições inerentes ao Sistema Financeiro Mundial (SFM), derivado de Bretton Woods. Vale observar que o SFM se apresenta de forma

6" The concept implies, of course, a circular constellation of forces tending to act and react upon one another in such a way as to keep a poor country in a state of poverty" (Myrdal, 1957, p. 13). Dado a ênfase de Myrdal sobre a incapacidade da teoria econômica não possuir instrumentos apropriados para gerenciar os problemas de desigualdades regionais, a partir do equilíbrio geral para explicar os desequilíbrios regionais (Lima; Simões, 2009). Contudo, Myrdal não explora a problemática da exclusão financeira no contexto do desequilíbrio regional. 
muito particular em relação ao espaço. Sua espacialidade se baseia numa constrição temporal e espacial, dentro de um circuito altamente restrito, expondo ilhas de excelência financeira, dos grandes herdeiros de Bretton Woods. Nesse sentido, seria uma necessidade histórica romper o padrão de reprodução do capital das suas condições históricas específicas e geoterritoriais a fim de buscar uma maior sorte no caso da periferia latino-americana.

O argumento de Harvey (2013) quanto à construção do território como algo edificado na própria dinâmica do desenvolvimento econômico e social, produzido, não se torna um legado da "natureza" ou da própria "história", mas se configura como resultado da intervenção e modificação dessa realidade:

As diferenciações geográficas então com frequência parecem ser o que elas realmente não são: meros residuais históricos em vez de aspectos ativamente reconstituídos dentro do modo de produção capitalista. Portanto, é importante reconhecer que a coerência territorial e regional, pelo menos parcialmente discernível dentro do capitalismo, é ativamente produzida em vez de passivamente recebida como uma concessão à "natureza" ou à "história". A coerência, como ela é, surge da conversão das restrições temporais para espaciais à acumulação. (HARVEY, 2013, p. 603).

O BID teria como função prover justamente a necessidade de oferta de crédito a fim de suprir o vácuo causado na região pela exclusão financeira. No caso particular da América Latina, a dinâmica financeira e suas variações geográficas de acesso ao sistema financeiro acabavam aprofundando e distorcendo ainda mais o "desenvolvimento desigual" (LEYSHON; THRIFT, 1997, p. 229).

Destarte, o BID, enquanto banco de fomento, teria que imprimir uma agenda que fosse compatível com essas preocupações de comprimir tempo e espaço, desenvolvimento e integração. Não obstante, a discussão sobre espacialidade não é instigada no interior do BID. Consequentemente, não se toca no papel a ser desempenhado pelo banco nesse processo.

A estratégia do Banco se fixa nos pilares de Bretton Woods, que fogem da perspectiva regional multiescalar ao sustentar no viés de políticas macroeconômicas. Esse processo denota as condições políticas e econômicas, que acabam afetando não 
apenas a oferta de crédito do Banco como o perfil desses créditos desde sua fundação, a partir das condições da geopolítica internacional (SOARES, 2016).

O acesso ao crédito do sistema financeiro é determinado pela adequação da riqueza. Este desenho financeiro da riqueza acaba por determinar o próprio crédito. É uma relação direta em que podemos observar uma geografia da renda, que é dada pela conveniência geográfica de acesso ao financiamento. Como destacam Leyshon e Thrift:

If gaining access to credit from the financial system is determined largely by income and wealth, then the geography of income and wealth shapes the geography of access to the system. But, as Dymski and Veitch (1992) argue, the relationship is an interdependent and circular one; the geography of income and wealth is determined in part by the geography of access to the financial system. (LEYSHON; THRIFT, 1997, p.229)

A configuração imposta por essa dinâmica na ação do BID deve ser interpretada a partir do Sistema Financeiro Mundial (SFM), pois a integração aos mercados financeiros globais implicou num paradoxo para América Latina. A inserção cada vez mais explícita ao SFM repercutiu num distanciamento regional (VIDAL, 2006, p. 49), impossibilitando a consolidação de políticas de integração.

O resultado foi perverso: com a inversão dos riscos, o mercado passou a socializar os seus riscos com o a sociedade. Em linhas gerais, intensifica-se a relação crédito-renda, constituindo ilhas de crédito num oceano de exclusão creditícia.

A imposição de diretrizes e normas dos organismos internacionais aprofunda a exclusão financeira, dificultando a integração. "If gaining access to credit from the financial system is determined largely by income and wealth, then the geography of income and wealth shapes the geography of access to the system" (DYMSKI, 2005, p. 441). Além disso, a relação se torna mais perversa no sentido de acesso aos mecanismos de créditos, esgarçando o tecido espacial [...] he relationship is an interdependent and circular one; the geography of income and wealth is determined in part by the geography of access to the financial system". (DYMSKI, 2005, p. 441).

O perfil dos empréstimos praticado pelo BID (os quais analisaremos nos próximos tópicos), em consonância com as diretrizes de mercado, acaba por distorcer ainda mais a integração regional e comprometer o desenvolvimento econômico. 
A opção ao SFM deu ao BID o papel de interlocutor dos mercados financeiros junto aos países da região, abdicando da integração regional enquanto projeto político e econômico. Assim se faz urgente uma releitura da estratégia creditícia do BID, enquanto resposta a lógica renda crédito.

\section{O BID e a Integração Regional}

Essencialmente estamos sinalizando não apenas a dificuldade de mobilizar outras instituições financeiras na América Latina, mas o papel delineado pelo BID, bloqueando assim outras instituições que pudessem apresentar uma alternativa concreta na constituição da integração regional.

A integração regional não foi uma prioridade estratégica, repercutindo assim no conjunto das demais instituições da região, como Banco Centro-Americano (BCA), Instituto de Interação da América Latina (INTAL), Fundo de Prevenção da Integração da América Latina (SOARES, 2016) ${ }^{7}$. Em sua particularidade, o BCA desempenharia um papel relevante em termos propositivos, porém restrita em sua capacidade financeira. As instituições de fomento na América Latina não foram capazes de gerar um efeito multiplicado e integracionista. BCA, INTAL e o Fundo de Prevenção da Integração obtiveram pouca eficácia no processo de integração, não conseguindo comprimir o espaço tempo. A atuação do BID impôs um dinamismo de distanciamento entre essas instituições, pautada pela agenda do BID em sua dimensão e suas diretrizes impostas na região (SOARES, 2016).

A repercussão da presença do BID infringe uma série de limites à constituição de oportunidades regionais, tanto pelo seu peso político como pelos seus projetos de financiamentos. Sob esse aspecto vamos considerar as linhas gerais de liberação de recursos nos primeiros dez anos do banco.

\footnotetext{
${ }^{7}$ No caso do BCA, que demandava recursos com objetivos de alavancar a integração entre as economias da América Central (articulado por meio de uma cadeia de indústrias integradas). Entretanto as ações do BCA buscavam não apenas a consolidação de um processo de integração econômica, sustentado num conjunto de políticas industriais, o BCA, iria além, apresentava certas condições para o rompimento de ciclo de crédito e renda na região.
} 
A tabela 1 descreve os projetos adotados pelo BID, na sua estratégia de liberação dos recursos para investimentos. A mobilidade dos investimentos nos joga luz sobre o perfil da estratégia, concentrando de forma bastante densa nos setores de transportes, energia elétrica, essenciais sim, mas que tiveram impactos limitados no processo de integração regional e pouco dinamizador da renda nas esferas locais. Essa estratégia selou o tipo de investimentos do Banco no decorrer de suas atividades nas décadas subsequentes - uma instituição de infraestrutura, $77 \%$ dos investimentos.

Tabela 1- Operações do BID no campo da integração, em 31 de dezembro de 1969 (em milhões de dólares).

\begin{tabular}{lcccc}
\hline Setores & $\begin{array}{c}\text { Pré } \\
\text { Investimentos }\end{array}$ & Investimentos & Total & $\%$ \\
& & & & \\
\hline Exportações intrarregionais de bens de capital & & 41,0 & 41,0 & 10,5 \\
\hline Infraestrutura & 12,9 & 290,4 & 303,3 & 77,7 \\
\hline Indústria & 0,6 & 21,2 & 21,8 & 5,6 \\
\hline Setor agropecuário & 0,2 & 15,6 & 15,8 & 4,0 \\
\hline Desenvolvimento de zonas multinacionais & 0,8 & & 0,8 & 3,0 \\
\hline Ensino Superior & & 2,9 & 2,9 & 7,0 \\
\hline Treinamento e difusão & 2,9 & & 2,9 & 7,0 \\
\hline Apoio institucional & & & 1,8 & 5,0 \\
\hline Total & 17,4 & 371,1 & 390,3 & 100, \\
& & & & 0
\end{tabular}

Fonte: Banco Interamericano de Desenvolvimento (BID) -1969.

Os setores com capacidade de gerar efeitos multiplicadores regionais, como o caso de exportações intrarregionais e bens de capital e o do desenvolvimento de zonas multinacionais, receberam um volume modesto de recursos, bem desbalanceada.

A opção do BID por investimentos robustos nos setores de exportações intrarregionais e bens de capital e o do desenvolvimento de zonas multinacionais poderia vir a afetar, interferir, na ação das empresas estadunidenses na região. Podemos confirmar essa preocupação em pelo menos um instante: 
Embora não haja provas de que os investidores norte-americanos tenham expressado qualquer desaprovação à 'indústrias integradas' a funcionários governamentais categorizados, é bem possível que isso tenha sido expresso em caráter privado. O fato de o esquema de 'indústrias integradas' apresentar várias características que possam ser objeto de objeções por parte de investidores norte-americanos poderá, mesmo na ausência de pressões abertas, ter influenciado a posição assumida pelo Governo dos Estados Unidos (WIONCZEK, 1964, p.78).

O que fica do exposto é a perceber que os setores nos quais se concentrou a maioria dos empréstimos são basicamente setores ligados à demanda do mercado interno de bens de consumo e aqueles ligados à exportação de matérias-primas (mineração: 27,1\%; petróleo e carvão: 33,6\%), com baixa intensidade de capital e que se mostram incapazes de constituir cadeias regionais de fornecedores, conforme a tabela 2 nos demonstra, reforça assim o perfil dos recursos liberados pelo banco.

A partir da tabela 2, podemos estender a linha temporal até o ano de 2000 , e verificarmos a consolidação de perfil do banco desde seus primeiros anos. O setor produtivo nunca esteve no radar das prioridades do BID, enquanto a reforma e modernização do estado ficaram com a maioria absoluta dos recursos, não observamos investimentos em projetos que fossem capazes de gerar alguma capilaridade na região. Os investimentos em setores como exportações intrarregionais e bens de capital e o do desenvolvimento de zonas multinacionais ficaram praticamente esquecidos.

Mais do que isso, muitos desses investimentos refletem a falta de uma linha mestra, como bem chama a atenção Bloch, no Boletim das Nações Unidas:

Algunas de las primeras actividades del Banco Interamericano de Desarrollo consistieron en la continuación de determinados estudios del BIRF. Por ejemplo, el Banco había efectuado planes para llevar a cabo proyectos regionales en el sector de las telecomunicaciones en América Central, y para la construcción de una carretera panamericana, antes de que el BID iniciase sus operaciones. Tanto en estas actividades como en otras muchas, el BID coordinó sus actividades con las del BIRF. Además, los dos Bancos han participado conjuntamente en grupos consultivos que han operado en Ecuador y en Colombia, dirigido el primero por el BID y el segundo por el BIRF (BLOCH, 1969, p. 4-5). 
Tabela 2 - Distribuição dos empréstimos por setor (em milhões de dólares)

\begin{tabular}{|c|c|c|c|c|}
\hline Setor & $1961-2000$ & $\%$ & 2000 & $\%$ \\
\hline Setores produtivos & US\$11.972,7 & 11,2 & US\$ 165,4 & 3,1 \\
\hline Agricultura e pesca & $10.577,40$ & 9,9 & 311,2 & 5,9 \\
\hline Ciência e tecnologia & $1.676,30$ & 1,6 & 133,3 & 2,5 \\
\hline \multicolumn{5}{|l|}{ Infraestrutura física } \\
\hline Energia & $16.415,10$ & 15,4 & 436,8 & 8,3 \\
\hline Transportes e comunicações & $12.827,40$ & 12,0 & 434,8 & 8,3 \\
\hline \multicolumn{5}{|l|}{ Setores sociais } \\
\hline Saneamento & $9.015,00$ & 8,5 & 145,0 & 2,8 \\
\hline Desenvolvimento urbano & $6.655,10$ & 6,2 & 685,0 & 13,0 \\
\hline Educação & $4.466,60$ & 4,2 & 270,8 & 5,2 \\
\hline Investimento social & $7.426,60$ & 7,0 & 617,9 & 11,7 \\
\hline Saúde & $2.138,70$ & 2,0 & 10,6 & 0,2 \\
\hline Meio ambiente & $1.493,30$ & 1,4 & 142 & 2,7 \\
\hline Microempresa & 386,00 & 0,4 & Zero & 0 \\
\hline \multicolumn{5}{|l|}{ Outros setores } \\
\hline \multicolumn{4}{|l|}{ Estado } & 35,8 \\
\hline $\begin{array}{ll}\text { Financiamento } & \text { de } \\
\text { exportações } & \end{array}$ & $1.545,80$ & 1,4 & 16.8 & 0,3 \\
\hline Pré-investimento e outros & $2.301,50$ & 2,2 & 12,0 & 0,2 \\
\hline Total & US\$106.607,3 & & US\$5.26 & \\
\hline
\end{tabular}

Fonte: Relatório Anual do BID (2000).

Enfim, o BID desenvolveu uma série de projetos constituídos fora de sua estrutura, perdendo, em muito, sua capacidade de reflexão independente e ação criativa. Limitou-se, em muitos momentos, a refletir as ações de outras instituições internacionais.

\section{O BID a Integração Regional e o Sistema Financeiro Mundial}

O primeiro presidente, Felipe Herrera, destacava sua estratégia de um banco regional, capaz de desenvolver projetos de integração regional (SOARES; BRAGA, 
2017, HERRERA, 1968). O fato de o BID ter um papel importante na América Latina não valida sua autonomia em relação às demais instituições financeiras internacionais, uma vez que seu peso é relativizado enquanto instituição de desenvolvimento assim como sua força política financeira.

O BID, juntamente com as demais instituições ou bancos multilaterais, independente, não conseguem produzir um sistema monetário autônomo ou consolidar redes regionais influentes na base do sistema bancário, com autonomia de financiamento a partir de uma cesta de moedas regionais. São incapazes de agir como bancos de desenvolvimento, referenciais nas suas regiões e cumprir a função de integradores regionais.

Não são efetivamente, instituições que conseguem responder de forma adequada ao que denominamos integração regional e seu desenvolvimento. Contrariando Sagasti (2002), a interseção propositiva não nos parece se sustentar. Não responde de fato às condições concretas das instituições regionais de financiamento; em suma, apenas esboça um sistema de relação que na realidade coloca essas instituições como agentes passivos no que de fato se molda a estrutura de herdade do desenho de Bretton Woods, preso de forma sistêmica ao padrão dólar de financiamento e às reconfigurações econômicas dos anos 90 .

O questionamento não está dado em sua essência no seu papel institucional, enquanto organismo de financiamento, mas sim pelos seus limites institucionais, tornando-se assim mecanismo ou mesmo correia de transmissão das políticas das grandes instituições oriundas do modelo de Governança Global do pós-guerra8.

Há um engano recorrente arrazoar que uma maior participação dos empréstimos globais oriundos de instituições regionais viesse a assumir um espaço deixado pelas grandes instituições internacionais. O que se tem de ocorrência é uma alteração em algumas funções. Os bancos multilaterais e o BID em especial passam a trabalhar num aspecto que é justamente de aliviar o Banco Mundial e até mesmo o Export-Import

${ }^{8}$ A governança global pós-guerra, foi a constituição de um conjunto de instituições (ONU, FMI, BM, OTAN) políticas, diplomáticas, econômicas, a fim de normalizar relações econômicas e políticas, como políticas comercial e cambial e de segurança. 
Bank of the United States (EXIMBANK). Com isso, mais do que nunca, essas duas instituições passam a exercer papéis de elaborações de políticas globais.

O BID, no final do século XX e começo do século XXI, mais do que qualquer época, passou a trabalhar como executor de políticas de caráter neoliberais, distanciando-se definitivamente do que seria a base das teses desenvolvimentistas:

Las políticas y programas del BID en materia de integración regional adquirieran un nuevo impulso y adoptaron un nuevo foco a partir de los años ochenta... Un aumento significativo de los recursos temporal por parte del Banco Mundial, el BID reflotó sus actividades de apoyo : a) asistir a los gobiernos en los programas de ajuste orientados a la liberalización del régimen comercial, la participación en las negociaciones de la Ronda de Uruguay e la inserción en el proceso de globalización, b) estimular la cooperación intrarregional en materia de comercio y negocios, con especial énfasis en el sector privado: y c) promover la integración física. (BOUZAS; KNAACH, 2009 p. 22).

Esse aporte de recursos descrito por Bouzas e Knaach (2009) indica um fim de uma perspectiva teórica a propósito de um entendimento teórico marcado pelo pensamento estruturalista e institucional que ainda resistira no interior do $\mathrm{BID}^{9}$. As políticas creditícias e as áreas estratégicas do Banco tiveram como meta promover uma agenda pró-mercado na promoção de acumulação de capital privado, "créditos a condición de reformas políticas", de cunho neoliberal (VIVERAS, 2013, p. 114-115).

El principal de esos temas concernía a la participación del Banco en los esfuerzos por apoyar con préstamos sectoriales las reformas de política económica de los países, actuando en concierto con el FMl y el Banco Mundial. El 17 de diciembre de 1987, en este marco de divisiones y desencuentros, se produjo la renuncia del Presidente Ortiz Mena. Afortunadamente, dentro del proceso para la elección de un nuevo presidente pudo apreciarse pronto un claro apoyo mayoritario al ministro de Relaciones Exteriores de Uruguay, Enrique V. Iglesias, quien resultó electo por unanimidad (BID. 2013, p.40)

O BID é estruturado dentro de um cenário defensivo em termos de elaboração teórica alternativa, em contraposição ao pensamento liberal que volta depois do esgotamento do modelo desenvolvimentista e frente à crise da dívida externa dos

9 En este período, el mandato del BID para el desarrollo estuvo dominado por dos perspectivas complementarias que guiaban oficialmente las acciones del Banco: los programas de ajuste estructural (PAE) desarrollados en primeira instancia en periodo de 1990-1994, y la segunda geración de reformas (SGR) entre 1961-2001, creadas pelo FMI (VIVARES, 2013, p115). 
países da América Latina (BID, 1999, p.105). O Banco é situado dentro de uma grave crise econômica e institucional que leva a uma perda ainda maior da capacidade de formulação econômica e política (BID, 1999, p. 82) ${ }^{10}$. Nesse quadro de deterioração de políticas desenvolvimentistas, o papel do BID se consolidou como um ator coadjuvante, na formulação de políticas públicas. O BID mostra-se como uma correia de transmissão das demais instituições internacionais (FMI, BM).

El aumento del capital en US\$26.500 millones y el de los recursos concesionales en US $\$ 200$ millones, lo que permitiría financiar un programa de préstamos de US $\$ 22.500$ millones para el cuatrienio 198993; la creación de un procedimiento especial que permitiría la postergación sucesiva de un préstamo hasta por 12 meses a solicitud de dos o más directores ejecutivos; el levantamiento de los topes de préstamos para los países del Grupo A4, y el compromiso de destinar no menos de $75 \%$ del programa de $1990-93$ al financiamiento tradicional de inversiones, utilizando hasta $25 \%$ de los fondos del aumento para programas de ajuste sectorial. Respecto de esto último, se dispuso que durante los primeros dos años del cuadrienio el BID cofinanciara programas de esta naturaleza con el Banco Mundial para aprovechar la experiencia que esta otra institución había acumulado en la materia. Pasado ese lapso, el BID debía asumir la responsabilidad plena de sus operaciones de tipo sectorial. Este acuerdo requería la convalidación pormenorizada del Comité de la Asamblea y la ratificación ulterior de la Asamblea de Gobernadores. El Comité se reunió en sesión continua durante 42 horas para completar sus deliberaciones antes de la clausura de la Reunión Anual, prevista para el mediodía del miércoles 22 de marzo. En esas horas finales culminaron tres años de deliberaciones. Los plazos y formalidades se cumplieron. El Comité aprobó el documento del Séptimo Aumento a tiempo y lo elevó a la consideración formal de la Asamblea de Gobernadores, donde fue ratificado el 25 de enero de 1990. (BID, 2013, p 44).

O que podemos ressaltar é a marginalização do BID em termos propositivos. No quadro 01 a seguir, chamamos a atenção a essa interpretação justamente ao colocar o BID numa situação deslocada desse Sistema Financeiro Mundial (SFM). Esse quadro se aprofunda drasticamente com consolidação das teses da globalização, estreitando assim qualquer relação de interpretação com viés mais regional, tanto na condição do desenvolvimento, quanto na percepção de um sistema financeiro regional autônomo.

\footnotetext{
10 A crise da dívida externa na década de 1980 e a crise econômica Mexicana de 1994-1995 e Argentina de 1995 expõe a incapacidade de resposta e a fragilidade do BID no seu papel de agência de fomento e integrador econômico.
} 
Economists and policy-makers have largely interpreted financial globalization as involving the homogenization of formerly idiosyncratic national systems. One approach within economic theory has then been recruited to demonstrate the superior efficiency (hence logical necessity) of homogenized (and therefore modern) financial systems. This is the angle of insight of most IMF and World Bank economists. (DYMSKI, 2005, p.440).

O BID se coloca na base do sistema dado que pela nossa interpretação, observamos que essa instituição está em interseção de forma dependente as duas grandes instituições de Bretton Woods. O desenho do BID e sua relação com o sistema financeiro internacional é dada pela mediação em relação às instituições multilaterais como o FMI e o BM (LEYSHON; THRIFT, 1997).

Nesse ponto, o papel de um banco de fomento se caracteriza e se consolida como um agente de funções definidas, segundo o qual; "si existe um papel para Banco Regional de Desarrollo, entonces, este es el de promover este camino de desarrollo de mercado" (VIVARES, 2013, p. 22).

A missão que se estabelece como possível no interior dessas instituições de fomento é moldado pelo mercado: dependência em relação aos mercados de capitais como fonte de recursos para os países periféricos; integração financeira total e, por fim, ajuste estrutural interno através da abertura comercial e financeira (VIVARES, 2013).

A extensão da dependência em relação ao aval de emissões de títulos junto ao mercado internacional no intuito de alavancar expediente denota, desta forma, a necessidade de abono por parte dessa instituição, ou mesmo correia de transmissão de políticas acordadas na esfera superior.

O banco, a fim de atuar na superestrutura financeira internacional junto à banca privada como captador de recursos e ao mesmo tempo como emprestador ao setor privado produtivo, e também com a intenção de dinamizar ações de desenvolvimento na região em setores excluídos, apresenta uma atuação incongruente com a dinâmica do espaço crédito.

A questão mais importante que queremos destacar é a limitação das ações desse Banco de Desenvolvimento, em termos de condução de políticas de desenvolvimento e integração regional. 
Con el Octavo Aumento el capital autorizado se incrementó en US $\$ 40.000$ millones y los recursos del FOE, en US $\$ 1.000$ millones, dándole al Banco la capacidad financiera de alcanzar y de sostener un nivel de alrededor de US\$8.000 millones anuales en nuevos préstamos. A su vez se ajustaron las proporciones de participación de los diferentes grupos de accionistas: la de los extra regionales aumentó del $7 \%$ al $16 \%$, mientras que la del resto se redujo a una fracción superior al $50 \%$ para los países prestatarios, 30\% para Estados Unidos y $4 \%$ para Canadá. El Presidente Iglesias realizó intensas gestiones para lograr responder a una vieja aspiración de los países no regionales: el aumento de participación relativa en el capital del Banco. Como resultado, la participación de este grupo de países pasó del $8 \%$ al $16 \%$ del capital. Con ello no sólo se abrió la puerta para aportes al capital sino también para importantes contribuciones como las realizadas por el gobierno japonés, al Fondo Especial de Japón, al Fomin y al FOE. (BID. 2013, p. 47).

Gráfico 1- Sistema Financeiro Mundial

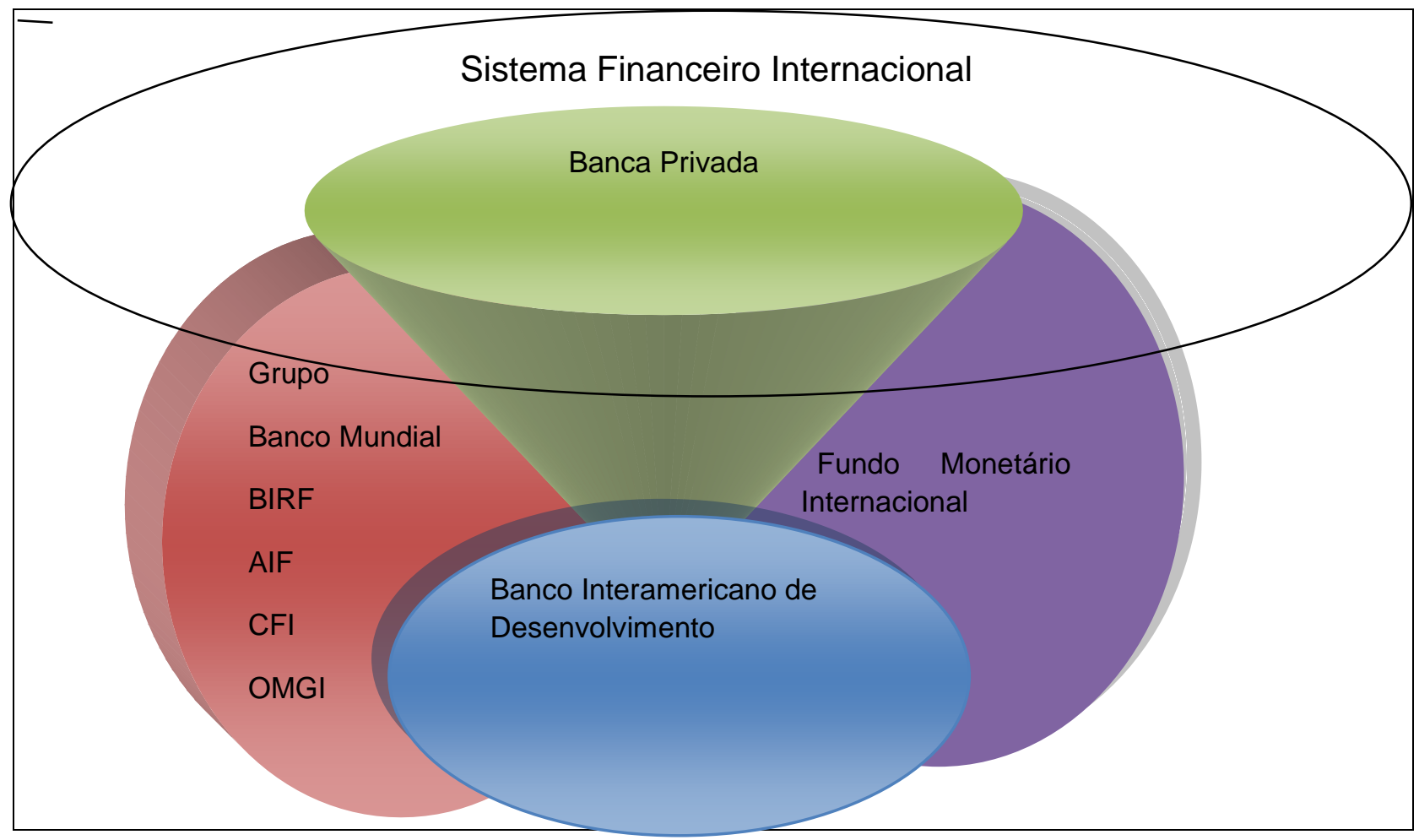

Fonte: elaboração própria a partir das ideias de Sagasti et al (2002). 
Desta forma, evidencia-se um maior aporte de capitais junto ao BID, oriundo dos países desenvolvidos de fora da região. A dependência dos capitais externos aumenta sua vulnerabilidade; mesmo com uma diminuição dos aportes dos E.U. A, a influência nos rumos da instituição não diminui.

Ao olharmos atentamente para os dados referentes ao desenvolvimento do sistema financeiro regional, observamos seu comprometimento em torno da relação renda-crédito.

\section{O BID os Bancos Regionais e o Sistema Financeiro Regional}

O BID, como as demais instituições de fomento, desde o iniciou precisou contar com a intermediação dos E. U. A, para atuar junto ao Sistema Financeiro Mundial. É fato que na década subseqüente ao final da segunda guerra surge uma série de instituições de financiamento regional com características particulares ${ }^{11}$.

Seria necessária a constituição de um sistema financeiro regional com base na integração do espaço, como destacam Titelmam e Cadelnty (2016, p. 211), no intuito de acionar uma série de eventos:

i) promover un fondo de reservas con cobertura regional para responder a las necesidades de financiamiento de las balanzas de pago y contribuir a la estabilidad financiera de la región, lo que implica aumentar la cobertura geográfica y (...) aumento de su capital y el acceso a nuevas fuentes de recursos; ii) potenciar el uso de los bancos de desarrollo regionales, subregionales y nacionales a través de nuevos instrumentos para el financiamiento de la inversión productiva y el comercio, y iii) potenciar los acuerdos de sistemas de pago entre bancos centrales para dinamizar el comercio intrarregional y mejorar la colaboración y la cooperación entre bancos centrales e instituciones financieras de la región (TITELMAM; CADELNTY, 2016. p. 211)

\footnotetext{
11 The Inter-American Development Bank (IDB); the Asian Development Bank (AsDB); the African Development Bank (AfDB); and the European Investment Bank (EIB). Strong political motivations led to their creation in the 1950s and 1960s. The first two institutions may be viewed as the result of cold war politics, while the third is the daughter of decolonization. EIB was born, in turn, out of two basic objectives of European integration: to support lagging regions and thus an equitable integration process; and to finance the investment in the infrastructure of integration - "regional public goods" in current terminology. To these we should add the European Bank for Reconstruction and Development (EBRD), which was established in 1991 and is the daughter of post-cold war politics. (OCAMPO. 2006, p.12-13).
} 
Desta forma, um banco de desenvolvimento latino-americano teria como marco teórico um reordenamento frente à estratégia liberal baseada na livre circulação de mercadorias e de capitais, sob a premissa das vantagens comparativas, lógicas que norteiam o Fundo Monetário Internacional e o Banco Mundial (BONIFAZ, 2006) ${ }^{12}$.

Enquanto um banco de desenvolvimento, desenhado na condição de integrador e de cooperação financeira regional, teria como lógica sistematizar o processo de industrialização por substituição de importações (articulando cadeias produtivas regionais), assim com expandir sua base de exportação com maior peso na produção de bens agregados em ciência e tecnologia, assim como articulando sinergias regionais. O fundamental na integração regional seria desenvolver mecanismos financeiros regionais autônomos da esfera financeira internacional.

Ao reordenar o sistema financeiro regional para condução de políticas de integração regional, Vivares (2013) chama atenção para a condição conflituosa a ser gerada na própria organização de um sistema financeiro regional autônomo:

Así su intervención en el desarrollo regional y nacional distorsiona la dinámica natural de las fuerzas de mercado global y genera en los países incentivos negativos para implementar las reformas estructurales para acceder a una financiación externa de desarrollo" (VIVARES, 2013, p.20-21).

Desta forma, a construção de um sistema financeiro regional autônomo voltado para a integração regional se desdobra em duas frentes: i) política de desenvolvimento de integração regional; ii) política de financiamento autônoma - criação de um fundem descolada da sistemática financeira internacional.

As interações e propostas que nortearam a constituição de um sistema financeiro regional autônomo (instituição de fomento) vêm na condição de se compor como uma instituição capaz de fornecer condições de crédito para o desenvolvimento regional, uma resposta às condições que os países estão inseridos no SFM.

\footnotetext{
12“ El financiamiento al desarrollo, y por ende el ataque a la pobreza extrema, podría facilitarse si los bancos regionales de desarrollo (BRD), cumpliendo con los objetivos para que los que fueron creados abandonaram sus políticas acordes con las del Fondo y del Banco y crearan condiciones favorables a integración regional de los mercado financieros" (BONIFAZ, 2006, p. 104).
} 
A constituição de mecanismos financeiros regionais, a fim de romper a dinâmica da imposição da política de fora para dentro, aparece na própria criação do BID. Portanto, uma instituição de crédito autônoma, com mecanismos próprios de captação de fundos, é condição ímpar para determinar um projeto de integração. O BID representa, em sua essência, a contradição no que se refere a uma instituição financeira autônoma regional. Desta forma, Dam (1967) destaca:

Es curioso observar que en la fundación del Banco Interamericano de Desarrollo, en 1960, no se hace referencia alguna a la integración, palabra que no figura en los estatutos. En la actualidad, el doctor Felipe Herrera, su presidente, se refiere casi con mayor frecuencia al "Banco de la Integración" que a su título oficial. Si bien es cierto que hoy, en círculos oficiales y privados, es mucho lo que se escribe y se habla sobre la integración, poco es lo que se hace. Esta observación no debe interpretarse como crítica al secretariado de la Alalc en Montevideo. Es que el tratado de Montevideo es demasiado tímido, demasiado estrecho en su concepto, como para visualizar una integración económica. No refleja sino el temor de industriales a la competencia regional, y de los gobiernos a la idea de una autoridad supranacional. Mientras los industriales no acepten la competencia a nivel regional, tal como ya existe a nivel nacional, y mientras los gobiernos no admitan someter su planeamiento económico de largo plazo a una entidad coordinadora, ejecutiva y supranacional, muy reducidas serán las esperanzas de que el espíritu de la integración se transforme en estrecha cooperación regional (DAM.1967, p. 88).

Nesse formato, tudo é demasiado precário em termos de fixação das metas, limitadas por um conjunto de interesses extra-regional. Podemos nos apropriar do sistema geral apresentado por um modelo das instituições de fomento que surge após a Segunda Guerra e que nos dará uma perspectiva ampla sobre o verdadeiro espaço e os limites de interação dos Bancos Regionais de Desenvolvimento (BRD). Os BRD nunca se tornaram de fato o tripé dessa ordem do Pós-Guerra, como pode às vezes transparecer, enquadrando-se entre o $\mathrm{FMI}$ e o BM. O panorama que é apresentado é nítido sobre a posição subordinada dos BRD frente ao complexo circuito institucional de sustentabilidade de Bretton Woods e, em última instância, do monopólio do dólar sobre o mundo.

Os BRDs não ocupam uma posição de centralidade, nem de influência no SFM. No máximo, o que desempenham é uma influência consentida no tabuleiro regional, 
com bases limítrofes da sua influência e com baixa relevância institucional. Seus limites baseiam-se em articulações limítrofes no campo do fomento do desenvolvimento e ainda muito mais estreito se comparar com algumas propostas de agências de fomento anteriores à sua criação (SOARES, 2016).

O BID esteve longe das ideias originais, em particular enquanto uma instituição de desenvolvimento que pudesse representar uma mudança estrutural nas condições de financiamento latino-americano e baseada no conjunto de propostas que se colocavam a partir de uma instituição financeira capaz de articular a integração regional.

A lógica do SFM tem como sua principal meta a desregulamentação do mercado financeiro, de forma a fluir os capitais sem nenhum entrave à sua circulação. Ao fazer parte desse cenário de forma subordinada o BID e aos demais BRDs, intensifica a relação renda-crédito e a descompactação dos espaços regionais.

$\mathrm{O}$ BID e os demais BDRs acabam se consolidando de forma diferente ao princípio internacional, no sentido de ser um agente para compor o SFM, não como estabilizador, nem como financiador de projeto de desenvolvimento e integrador regional ou de possuir um desempenho ativo no desenvolvimento regional, mas como agente de reprodução da política econômica gestada no SFM. Essa é uma fragilidade inerente aos Bancos, desde sua criação, que se aprofunda cada vez mais.

Essa configuração de instituições de fomento que surgem independente do seu perfil e do tempo histórico, que estabeleceu seu corte geracional, dada as características particulares e da própria diferenciação geracional (histórica) e sua própria gênese, organiza-se via desenvolvimento de mercados de títulos regionais como as instituições vindas particularmente da Ásia Oriental. Essas novas instituições regionais se relacionam com o SFM como um todo, como é enfatizado por Sagasti:

El espacio de acción que puede denominarse financiamiento para el desarrollo se ubica en la intersección del "sistema de organizaciones internacionales de desarrollo" y el "sistema financiero internacional". En este espacio se sitúan diversas instituciones, tales como las organizaciones de las Naciones Unidas, las agencias regionales, las agencias bilaterales de cooperación, las fundaciones privadas, el Fondo Monetario Internacional (FMI) y los bancos multilaterales de desarrollo. Sin embargo, estos últimos ocupan un lugar privilegiado en dicha 
intersección, pues interactúan con todas las instituciones relacionadas con la promoción del desarrollo y las finanzas internacionales (SAGASTI. 2002, p.07).

Entretanto, essas interseções não se confirmam de forma propositiva no SFM. Independente do quadro que se coloca em relação ao novo perfil dessas instituições, há limites importantes para concluir que exista uma interseção de caráter determinante no interior do Sistema Financeiro Mundial no século XXI, como alguns autores colocam (CULPEPER, 2006; OCAMPO, 2006; SAGASTI; PRADA, 2006; ALCAS, 2005). A cooperação financeira regional e o estabelecimento de mecanismo de créditos que fujam ao círculo vicioso crédito renda. As instituições financeiras devem possuir um prisma que venha comprimir o espaço-tempo visando à eficiência da integração regional.

\section{Considerações finais}

A mudança estratégica de trocar fundos públicos por captação no mercado financeiro veio no bojo da construção do BID. Esta estratégia de captação afeta premissas básicas de independência e constituição de projetos de financiamentos. Ela passa a responder diretamente ao mercado financeiro privado, com grande pressão do sistema financeiro. A avaliação dos projetos passa a ser pautada mais pelas agências de risco do que pelos resultados dos projetos, repassando uma grande pressão aos países da região.

A situação fica mais crítica a partir da década de 1990, quando tanto o BID, como a maioria dos BRDs, ao estarem vinculados à elaboração política e à dependência financeira, acabam por não responder de forma efetiva à integração regional. Os projetos de financiamentos que observamos estão distantes de conseguirem estabelecer sistemas de sinergia, centros de transbordamentos de excelência na região, mecanismos de causa e efeitos no processo de integração.

O BID não é capaz de articular projetos de caráter econômico e social na condição de integração e seu papel passa ao largo no desenvolvimento de uma rede 
financeira que seja capaz de atuar na condição de romper a sistemática crédito renda, comprimindo o espaço-tempo.

Os projetos de financiamento precisariam estar comprometidos com uma ordenação dos investimentos, articulados com centros de pesquisa no campo acadêmico (ciência e tecnologia) que fossem desenvolvidos em espaços transfronteiriços, sedimentando a integração regional.

A exclusão financeira é resultado da orientação do BID na formatação dos fundos e precedida pela visão puramente de mercado. A condição estrutural de autonomia financeira e, consequentemente, de financiamento, passa pela constituição de um funding capaz de ofertar parte desses recursos para romper a sistemática crédito-renda. Por último, a falta de uma política de articulação de um sistema financeiro regional que traduza uma formulação parece bem mais próxima da resposta aos problemas macroeconômicos, impondo soluções externas para problemas específicos, aceitando uma agenda externa bem longe do que podemos chamar de "independente" no sentido de formar soluções muito mais criativas e lógicas dentro da realidade social, política e econômica da região.

Acrescenta-se, ainda, o papel que o BID assumiu na desarticulação das políticas de industrialização na região e nas orientações a desempenhar no processo de integração como agente financeiro regional ao núcleo das instituições do SFM. A escassez de crédito se constituiria então num importante fator de rompimento do ciclo de crédito renda. O desenvolvimento econômico e a integração regional fazem parte de um processo de criação de habilidades próprias, do qual o BID não é indutor.

O resultado é bem compreensível no que diz respeito ao que podemos chamar de um banco de desenvolvimento. Em outras palavras, não há espaço para designar o BID como um banco de desenvolvimento, ainda mais pelo seu baixo potencial de elaboração de políticas de desenvolvimento e de integração, em função de suas atividades de complementaridade e baixo impacto institucional e macroeconômico, não produzindo, de fato, uma concorrência junto à banca privada, nem mesmo desempenhando um papel mais incisivo junto ao SFM. O desenvolvimento econômico é um processo de criação de habilidades específicas de uma nação e de uma região; 
para isso, tem-se necessidade de constituir instituições que sejam capazes de fermentar esse processo.

\section{REFERÊNCIAS}

ALCAS, R. C. La banca de desarrollo en América latina. Unidades de Estudios Especiales. CEPAL, Santiago de Chile, septiembre del 2005.

AMIN, A.; TRIFFT, N. Globalization, Institutions and Regional Development in Europe. Oxford University Press, Oxford, 1994.

BANCO INTERAMERICANO DE DESARROLLO .BID. Convenio constitutivo del Banco Interamericano de Desarrollo - BID. Edición: Washington: BID, enero de 1969 [p.v.]

BANCO INTERAMERICANO DE DESENVOLVIMENTO (BID). Relatório anual do BID de 1999.

BANCO INTERAMERICANO DE DESENVOLVIMENTO (BID). Relatório anual do BID de 2000

BANCO INTERAMERICANO DE DESENVOLVIMENTO (BID). Relatório anual do BID de 2006.

BANCO INTERAMERICANO DE DESENVOLVIMENTO (BID). Relatório anual do BID de 2013.

$\mathrm{BLOCH}, \mathrm{H}$. S. Boletín Económico de América Latina. Financiamiento del Desarrollo Regional. NACIONES UNIDAS Vol. XIV, No. 1, Primer Semestre de 1969.

BONIFAZ, A. C. Cooperación Financiera Regional en Latinoamérica: posibilidades y obstáculos. In: Reforma Financiera en América Latina. Coordinado. Correa, E y Girón, A. Buenos Aires: Consejo latinoamericano de Ciencias Sociales, CLACSO, 2006.

BOUZAS, R. ; KNAACK, P. EI BID y médio siglo integración regional en América Latina y el Caribe. Integración \& Comércio. No 29 año 13. Enero- Junio 2009, p 15-27. BID/Sector de Integración y Comércio INTAL. Revista publicación Eletrônica Semestral.

CROCCO, M. ; JAYME, F, JR. Introdução. In: A moeda e território: uma interpretação dinâmica regional brasileira. (Org) Gonzaga e Crocco. Belo Horizonte: Autêntica 2006.

CULPEPER, R. Reforming the global financial architecture the potential of regional institutions. In: Regional financial cooperation. (Editor) Ocampo, J, A. UNITED NATIONS Economic Commission for Latin America and the Caribbean BROOKINGS INSTITUTION PRESS Washington, D.C. 2006. P. 40-67. 
DAM, A. V. El papel que juega el capital extranjero en América Latina. Los empresarios y la integración de america latina instituto para la integración de America Latina (INTAL). B. I. D. Instituto para la Integración de América Latina Banco Interamericano de Desarrollo Cerrito 264 - Buenos Aires1976. P, 81-100.

DYMSKY, G, A. From Financial Exploitation to Global Banking Instability: Two Overlooked Roots of the Subprime Crisis. https://www.researchgate.net/publication/228881879 (2007)

DYMSKY, G, A . Financial Globalization, Social Exclusion and Financial Crisis. International Review of Applied Economics, Vol. 19, No. 4, 439-457, October 2005

HARVEY, D. A condição pós-moderna: uma pesquisa sobre as origens da mudança cultural. São Paulo: Loyola, 1989 (3. ed.).

HARVEY, D. A produção capitalista do espaço. São Paulo: Annablume, 2005 (Coleção Geografia e Adjacências).

HARVEY, D. Serviço Social em tempo de capital fetiche: capital financeiro, trabalho e questão social" São Paulo: Cortez, 2008.

HARVEY, D. Os limites do Capital São Paulo: Boitempo, 2013.

HERRERA, F. O Desenvolvimento da América Latina e seu financiamento. APEC Editora S.A, 1968.

JESSOP, B. Capitalismo(s): discurso y materialidad em las formaciones sociales capitalistas contemporáneas. Córdoba. Univ. Católica de Córdoba, 2007.

LEYSHON, A. Geographies of Money and finance I. Progress in Human Geography, 19, 1995, p. 531-543.

LEYSHON, A.; THRIFT, N. Money/Space: geographies of monetary transformation. London: Routledge, 1997.

LIMA, A.C.; SIMÕES, R.F. Teorias do desenvolvimento regional e suas implicações de política econômica no pós-guerra: o caso do Brasil. Texto para Discussão; 358. CEDEPLAR, UFMG. BELO HORIZONTE, 2009.

MYRDAL, G. Economic theory and under-developed regions. Gerald Duckworth \& CO. LTD: London, 1957.

OCAMPO, J. A. La cooperación financiera regional: experiencias y desafíos. Cooperación financiera regional: In. OCAMPO, J. A. compilador: CEPAL, 2006 Santiago de Chile número 91, p. $13-56$

SARGASTI, S. La banca multilateral de desarrollo en América Latina. S E R I E. financiamiento del desarrollo Santiago de Chile, mayo de 2002, $n^{\circ} 119$. Unidad de Estudios Especiales Secretaría Ejecutiva. 
SARGASTI, S.; PRADA, F. Bancos regionales de desarrollo: una perspectiva comparativa. Cooperación financiera regional: In. OCAMPO, J. A. compilador: CEPAL, 2006 Santiago de Chile número 91, p. 91-130.

SOARES, J. A, R. O processo histórico de construção de uma instituição de fomento para América Latina: a economia política do BID. Tese de doutoramento, Programa de Integração da América Latina. Universidade de São Paulo (PROLAM/USP). 2016.

SOARES, J. A. R.; BRAGA, M. B. Felipe Herrera e o Banco Interamericano de Desenvolvimento (BID): uma disputa sobre os rumos do desenvolvimento na América Latina. Revista de Estudos \& Pesquisa sobre as Américas. V11, n. 2. 201, p.180-198.

TITELMAM, D.; e CADELNTY, E. P. 2016 Los espacios de cooperación e integración financiera. In: Regional en un mundo posterior a la crisis. Desarrollo e Integración en América Latina:

PRADO, A y CARNEIRO, R. Coordenada. CEPAL, BID, CAF, Instituto Lula. LC/G. 2674. Santiago do Chile, 2016. P. 209-258.

VIDAL, G. América Latina: banca, mercado de capital y determinación externa del crédito. In: Reforma Financiera en América Latina. Coordinado. Correa, E y Girón, A. Buenos Aires: Consejo latinoamericano de Ciencias Sociales, CLACSO, 2006.

VIVARES, E. EI Banco Interamericano de Desarrollo en la década neoliberal. FLACSO, sede Equador, Quito, 2013.

WIONCZEK, M. S. A integração latino-americana e a política econômica dos Estados Unidos. Rio de Janeiro: Editora Paz e Terra, 1969. Sítio consultado: http://www.oas.org/dil/esp/tratados C15 Convenio constitutivo del Banco Interamericano de Desarrollo.pdf

\title{
NOTAS DE AUTOR
}

\section{CONTRIBUIÇÃO DE AUTORIA}

José Alex Rego Soares - Concepção. Coleta de dados, Análise de dados, Elaboração do manuscrito, revisão e aprovação da versão final do trabalho.

Marcio Bobik Braga - Concepção. Coleta de dados, Análise de dados, Elaboração do manuscrito, revisão e aprovação da versão final do trabalho.

\section{FINANCIAMENTO}

Não se aplica.

\section{CONSENTIMENTO DE USO DE IMAGEM}

Não se aplica.

\author{
APROVAÇÃO DE COMITÊ DE ÉTICA EM PESQUISA \\ Não se aplica.
}

\section{CONFLITO DE INTERESSES}

Não se aplica.

\section{LICENÇA DE USO}

Este artigo está licenciado sob a Licença Creative Commons CC-BY. Com essa licença você pode compartilhar, 
adaptar, criar para qualquer fim, desde que atribua a autoria da obra.

HISTÓRICO

Recebido em: 29-11-2019

Aprovado em: 31-03-2021 